\title{
The sensorless control system for controlling the speed of direct current motor
}

\author{
Khac-Khiem Nguyen, Trong-Thang Nguyen \\ Faculty of Electrical-Electronic Engineering, Vietnam Maritime University, Vietnam
}

\begin{tabular}{l} 
Article Info \\
\hline Article history: \\
Received Apr 10, 2019 \\
Revised Jun 6, 2019 \\
Accepted Jul 7, 2019 \\
\hline
\end{tabular}

\section{Keywords:}

DC motor

Luenberger observer

PID control

Sensorless control

\begin{abstract}
This research aims to propose an algorithm for controlling the speed of the Direct Current (DC) motor in the absence of the sensor of speed. Based on the initial mathematical model of DC motor, the authors build the dynamic state equation of DC motor, and then build an estimation model to determine the speed of the DC motor without a sensor. The advantages of the proposed method are demonstrated through the closed-loop control model using the PID controller. In order for the results to be objective, we assume that the parameters of the DC motor in the estimation model are not known correctly. The results show that the quality of control in the absence of a sensor is equivalent to the case with the sensor.
\end{abstract}

Copyright $@ 2019$ Institute of Advanced Engineering and Science. All rights reserved.

\section{Corresponding Author:}

Trong-Thang Nguyen,

Faculty of Electrical-Electronic Engineering,

Vietnam Maritime University,

484 Lach Tray, Le Chan, Hai Phong, Vietnam.

Email: thangnt.ddt@ vimaru.edu.vn

\section{INTRODUCTION}

The Direct Current (DC) motor is a traditional electric motor. In comparison to the other electric motor such as brushless DC motors [1-3], induction motor [4-6], the intrinsic structure of the DC motor [7] has advantages such as the ease of maintenance, the simple control structure, the large electromagnetic torque, and the wide range of speed control. Therefore, DC motors are increasingly widely used in areas that require high-quality control, such as crane, elevator, conveyor, steel rolling, transportation, mining, etc [8], [9-13]. So, it is very important to reduce the cost of the control system, but enhance the performance of the DC motor. There is some research for controlling the DC motor such as [14-18]. Most of these researchers use a simple controller such as Proportional-Integral-Derivative (PID) controllers [19-20]. The advantage of the PID control is a simple structure, but the drawback is that the quality of the control system is not high. In the research [21], the author has proposed a method for controlling the DC motor that has achieved highquality, that is the control method based on the flatness principle, but the limitation of this method is that the control algorithm is complex. In the other research [22], the author has proposed a solution to build a control system based on the linear quadratic regulator controller, the control algorithm is simple and the quality is optimized.

In all above control methods, in order to achieve control requirements, it is required to determine the feedback values. These feedback values are normally determined via sensors. For example, if we need to control the speed of the DC motor, we need to have a sensor of speed (encoder). Adding these sensors makes the cost of the control system increase and the circuit structure of the control system becomes more complex. To overcome these limitations, in this study, the author proposes a solution to build a control system without the sensor. The authors build an estimation model based on Luenberger observer [23-25] to determine the feedback value which is the speed-value. These estimated values are applied as feedback signals in the 
closed-loop control system with the traditional PID controller. The control results in the absence of the sensor are compared with the result in the case with sensors to demonstrate the effectiveness of the proposed method.

The remnant of this research is structured as follows. The sate observer is introduced in Section 2. The design of the control system is presented in Section 3. The results and analysis are presented in Section 4, and lastly, in Section 5, some conclusions are presented.

\section{DETERMINING THE FEEDBACK VALUES USING THE STATE OBSERVER}

Considering the object with the state equation:

$$
\left\{\begin{array}{l}
\dot{X}=A . X+B . U+E . N \\
Y=C . X
\end{array}\right.
$$

Where: $X=\left[x_{1}, x_{2}, \ldots, x_{n}\right]$ is the vector of state signal.

$U=\left[u_{1}, u_{2}, \ldots, u_{m}\right]$ is the vector of control signal.

$Y=\left[y_{1}, y_{2}, \ldots, y_{k}\right]$ is the vector of output signal.

$N=\left[N_{1}, N_{2}, \ldots, N_{l}\right]$ is the vector of noise signal.

$A, B, E, C$ are matrices with the appropriate size.

The estimation of $X$ is $\widehat{X}$ which is defined by the state equation:

$$
\dot{\hat{X}}=A . \hat{X}+B . U+E . N
$$

The goal which needs to achieve is $\hat{X}=X$. This goal is solved easily if we know the initial value of $X(X(0)$, we will assign the initial value of $\hat{X}$ is $\hat{X}(0)=X(0)$. However, under the condition that the number of sensors is less than the number of state variables, we cannot know $X(0)$.

Named $X_{e}=X-\hat{X}$ is the error of the estimation. (1) minus (2), we have:

$$
\dot{X}_{e}=A \cdot X_{e}
$$

With the initial value of $X_{e}$ is $X_{e}(0)=X(0)-\hat{X}(0)$

If the object (3) is stable then $X_{e} \rightarrow 0$, it means $\hat{X} \rightarrow X$. The value of $\hat{X}$ is used for controlling the control object, so the kinetic speed of the observer must be much faster than the kinetic speed of the control object. Therefore, we add a forced component to the observer, this component is proportional to the difference between $Y=C . X$ and $C . \hat{X}$, the observer has the following equation:

$$
\dot{\hat{X}}=A \cdot \hat{X}+B . U+E . N+L(y-C . \widehat{X})
$$

With $\mathrm{L}$ is the constant matrix, transforming the (4), we have:

$$
\dot{\hat{X}}=(A-L \cdot C) \cdot \hat{X}+B \cdot U+E \cdot N+L \cdot y
$$

The diagram of the state observer in the absence of noise is shown in Figure 1. 


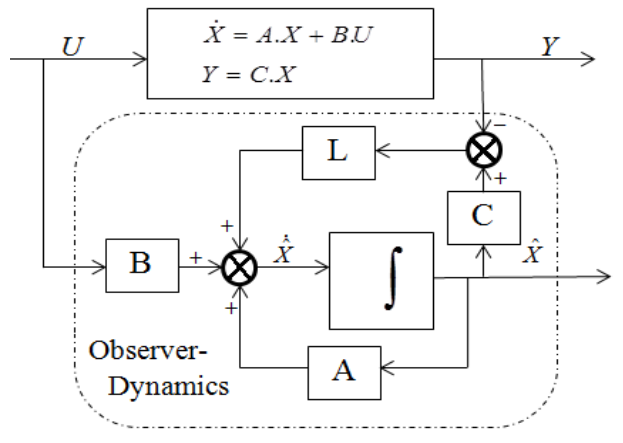

Figure 1. The diagram of the state observer

The state equation of the estimation error is as follows:

$$
\dot{X}_{e}=(A-L \cdot C) \cdot X_{e}
$$

The mission is to find $\mathrm{L}$ in order for the object (6) is stable, it means that $X_{e} \rightarrow 0$ and $\hat{X} \rightarrow X$. We must define $\mathrm{L}$ to impose the eigenvalue of (6) to the left of the virtual axis. These solutions must be a major solution in order for the kinetic speed of the observer must be much faster than the kinetic speed of the control object.

\section{THE SENSORLESS CONTROL SYSTEM FOR THE DC MOTOR}

\subsection{The Equations of the DC Motor}

The diagram of a separately excited DC Motor is presented as Figure 2 [22], it includes:

a) The field windings are in the stator, they are used to excite the field flux.

b) The armature coils are on the rotor, they are supplied current via brush and the commutator.

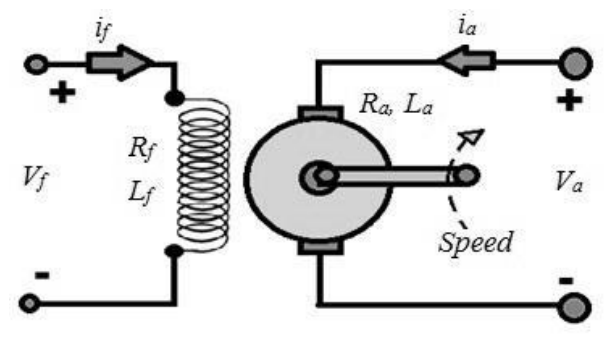

Figure 2. The diagram of a separately excited DC Motor

The mathematical equations of the DC Motor include:

The voltage equation:

$$
V_{a}=R_{a} i_{a}+L_{a} \frac{d i_{a}}{d t}+E
$$

Where $V_{a}$ is the armature voltage, which is fed into the armature coil; ${ }^{i}$ is the armature current; $R_{a}, L_{a}$ is the armature resistance and inductance; $\mathrm{E}$ is the electromotive.

The electromotive equation:

$$
E=K_{E} \omega=\left(L_{a f} \cdot i_{f}\right) \cdot \omega_{(\mathrm{V})}
$$


Where $\omega$ is the speed of the rotor, KE is the coefficient of voltage, ${ }^{i}{ }_{\text {is the winding field current, }} L_{a f}$ is the field armature mutual inductance.

The motion equation:

$$
J \frac{d \omega}{d t}=T_{e}-T_{L}-T_{f}
$$

Where $J$ is the inertia, $T_{e}$ is the electromechanical torque, $T_{L}$ is the torque which impact to the shaft, $B_{m}$ is the coefficient of the viscous friction, $T_{f}$ is the coulomb friction torque.

The electromechanical torque equation:

$$
T_{e}=K_{T} i_{a}=\left(L_{a f} \cdot i_{f}\right) \cdot i_{a}(\mathrm{~N} . \mathrm{m})
$$

Where $K_{T}$ is the torque coefficient.

\subsection{Estimating the Speed Value of DC Motor}

Based on the equations of the DC Motor, we build the state equation of DC Motor as follows:

$$
\left\{\begin{array}{l}
\dot{X}=A . X+B . U+E . N \\
Y=C . X
\end{array}\right.
$$

Where:

$$
\begin{aligned}
& X=\left[\begin{array}{c}
i_{a} \\
\omega
\end{array}\right] ; U=V_{a} ; N=T_{L}+T_{f} \\
& A=\left[\begin{array}{cc}
-R_{a} / L_{a} & -K_{e} / L_{a} \\
K_{t} / J & 0
\end{array}\right] ; B=\left[\begin{array}{c}
1 / L_{a} \\
0
\end{array}\right] ; E=\left[\begin{array}{c}
0 \\
-1 / J
\end{array}\right] ;
\end{aligned}
$$

We assume that the system has no sensor of speed (without encoder), so we must estimate the value of the speed $(\omega)$. Besides, we can determine the armature current value $\left({ }^{i}\right)$ through the current measurement circuit. Therefore, we have the following matrix C:

$$
C=\left[\begin{array}{l}
1 \\
0
\end{array}\right]
$$

The state equation of the estimation error is as follows:

$$
\dot{X}_{e}=(A-L \cdot C) \cdot X_{e}
$$

The mission is to find the matrix $\mathrm{L}$ in order for the convergence-speed of the object (13) much faster than the speed of the control object (11).

In order to investigate the efficiency of the proposed algorithm, we test the estimation-process of the speed value of the DC motor with the parameters shown in Table 1: 
Table 1. The parameters of the DC Motor

\begin{tabular}{cccccc}
\hline $\mathrm{Ra}(\Omega)$ & $\mathrm{La}(\mathrm{H})$ & $\mathrm{Kt}$ & $\mathrm{Ke}$ & $\mathrm{J}\left(\mathrm{kg} \cdot \mathrm{m}^{\wedge} 2\right)$ & $\mathrm{T}_{\mathrm{F}}+\mathrm{T}_{\mathrm{L}}(\mathrm{N} . \mathrm{m})$ \\
\hline 0.5 & 0.011 & 0.2 & 0.1 & 0.2 & $\mathrm{Var}$ \\
\hline
\end{tabular}

In order for the results are objective, we assume that the parameters of the DC motor are not known exactly. So, the DC motor parameters which used for the estimation algorithm are inaccurate, the details are as follows: Ra_id=0.9.Ra; La_id=0.9.La; Kt_id=Kt; Ke_id=1.1.Ke; J_id=1.1.J;

With the symbol "id" is used to indicate the parameters of the estimated plant.

Replacing the specific values of the parameters, we define the matrix A as follows:

$$
A_{i d}=\left[\begin{array}{cc}
-236.40 & -38.10 \\
41.38 & 0
\end{array}\right]
$$

The eigenvalue of $A_{i d}$ is as following:

$$
\text { Eig _ }_{-} A_{i d}=\left[\begin{array}{c}
-229.52 \\
-6.87
\end{array}\right]
$$

In order for the convergence-speed of the object (13) much faster than the speed of the control object (11), the following condition must be satisfied:

$$
\text { Eig _Value }\left(A_{i d}-L . C\right)=k . E i g \_A_{i d}
$$

Setting k=5, we have:

$$
\text { Eig_Value }\left(A_{i d}-\text { L.C }\right)==\left[\begin{array}{c}
-1147.6 \\
-34.35
\end{array}\right]
$$

Solving the (17) we have the following matrix L:

$$
L=\left[\begin{array}{c}
945.60 \\
-993.29
\end{array}\right]
$$

\section{RESULTS AND ANALYSIS}

In order to evaluate the entire results of the estimation process, we simulate the speed control system of the DC motor in the absence of the speed sensor. The simulation system model is shown in Figure 3.

In the control system, we use a simple controller such as a PID controller, with the parameters as follows: $\mathrm{Kp}=15, \mathrm{Ki}=20, \mathrm{Kd}=0$. The feedback speed value of the DC motor is normally determined by the sensor of speed (encoder). But in this proposed control structure, we don't need the encoder. The feedback speed value of the DC motor is determined by the state observer.

The results of the control system are shown in Figures 4 and 5. Figure 4 shows the results of the estimate-process of the armature current $\left({ }^{i}{ }\right.$ ). The results show that the estimated value of ${ }^{i_{a}}$ always follows the real value of $i_{a}$ with a very small error of estimation. 


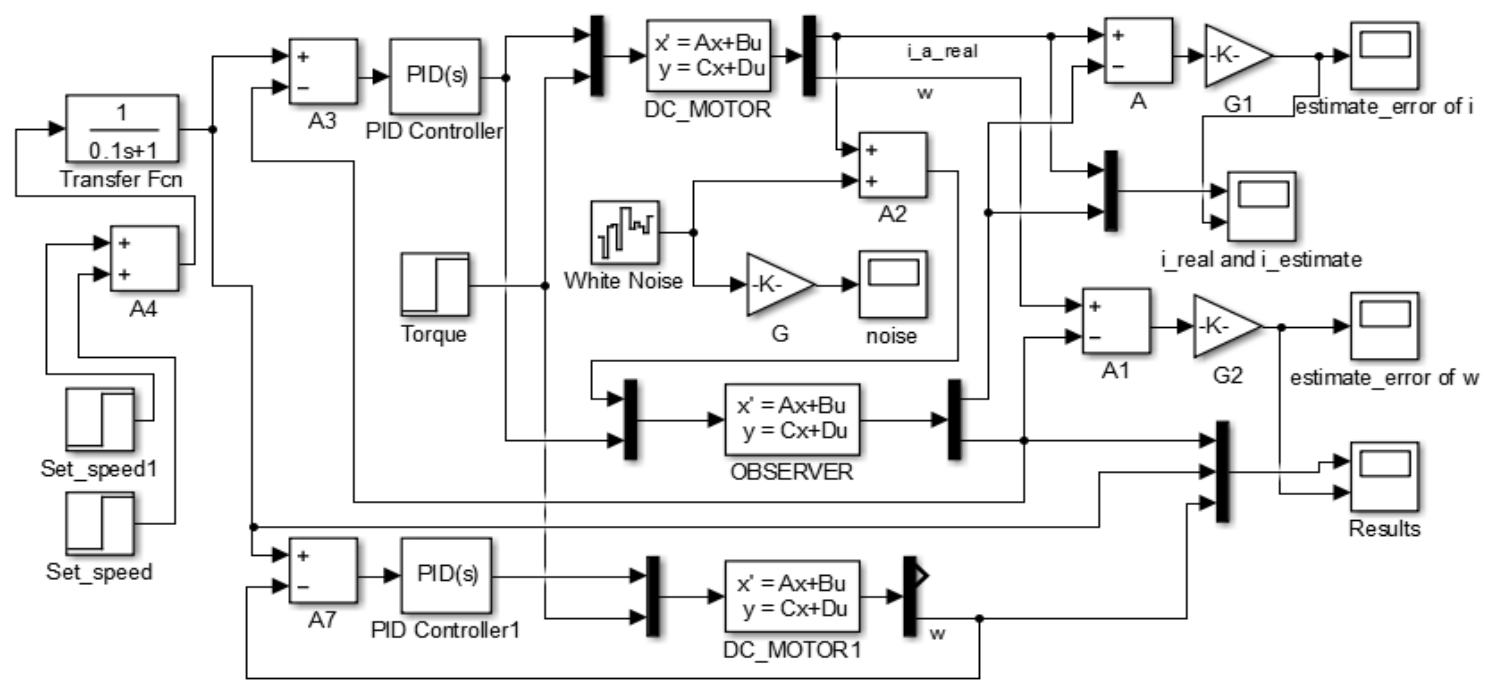

Figure 3. The simulation model of the control system
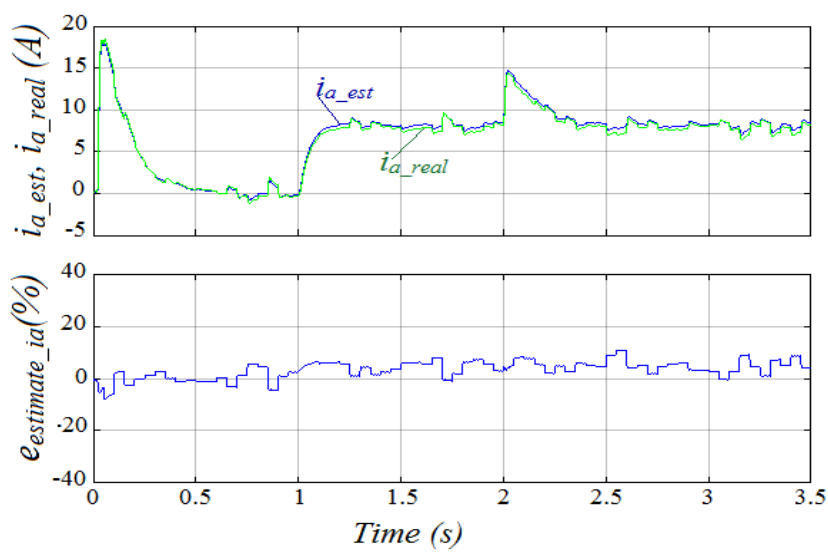

Figure 4. The results of the estimate-process of the armature current ${ }^{i}$

Figure 5 shows the results of the speed control process. The estimated value of the speed is feedback to provide the information for the PID controller.

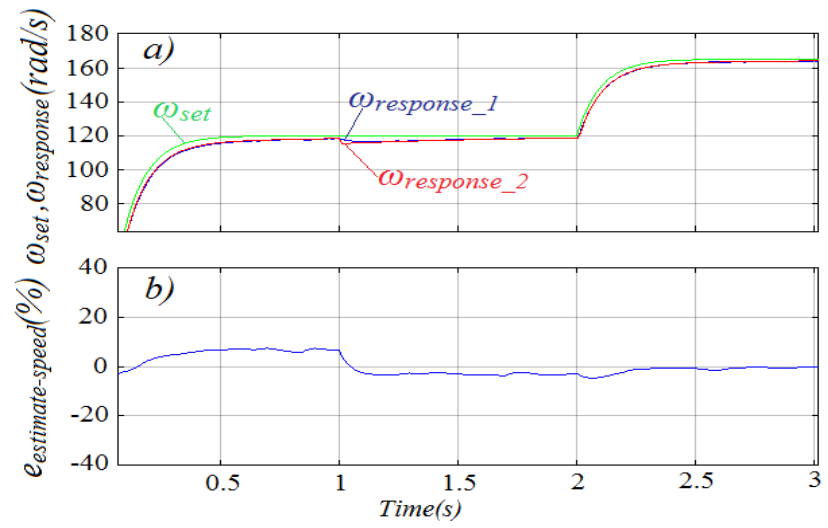

Figure 5. The results of the speed control process 
The results of Figure 5.b show that the estimated value of the speed always follows the real value of the speed with a very small error of estimation (eestimate-speed). The accuracy of this speed estimation has contributed to improving the quality of the control system. The response speed always follows the desired speed with a very small error of the control. The results of Figure 5.a show the speed control results in the absence of a sensor and in the case with sensor, it is included the following characteristic: the desired speed ( $\omega$ set), the response speed in the absence of sensors ( $\omega$ respnonse1), the response speed in the case with sensor ( $\omega r e s p n o n s e 2)$. The results show that the control qualities of these two cases are equivalent. Therefore, we can conclude that the superiority of the proposed algorithm is to reduce the cost of the control system because of the absence of a sensor while the control quality is still guaranteed.

\section{CONCLUSION}

In this study, the author has succeeded in building the control system of DC Motor in the absence of a speed sensor. The effectiveness of the proposed system is verified through a simulation model in the case the DC parameters are not known correctly. The results show that the estimated values of speed always follow the real value of speed with a very small error of estimation. This accuracy has contributed positively to improving the control quality. The results of the non-sensor control system are compared to the results of the sensor control system. The results show that the control qualities of these two cases are equivalent. Therefore, we can conclude that the superiority of the proposed algorithm is to reduce the cost of the control system while the control quality is still guaranteed.

\section{REFERENCES}

[1] Sekhar, G. R., \& Banakara, B. (2018). An Internal Current Controlled BLDC Motor Drive Supplied with PV Fed High Voltage Gain DC-DC Converter. International Journal of Electrical and Computer Engineering (IJECE), 8(2), 1262.

[2] Park, J. S., \& Lee, K. D. Design and Implementation of BLDC Motor with Integrated Drive Circuit. International Journal of Power Electronics and Drive Systems (IJPEDS), 8(3), 1109-1116, 2017.

[3] Trong, T. N., \& Duc, M. N. (2015). The speed control system of BLDC using PID controller with PWM modulation technique. International Journal of Advanced and Appied Sciences (IJAAS), (2(12), 47-51.

[4] Gunabalan, R., \& Subbiah, V. Speed Sensorless Vector Control of Induction Motor Drive with PI and Fuzzy Controller. International Journal of Power Electronics and Drive Systems (IJPEDS), 5(3), 315, 2015.

[5] Abdelhak, B., \& Bachir, B. A High gain observer based sensorless nonlinear control of induction machine. International Journal of Power Electronics and Drive Systems (IJPEDS), 5(3), 305, 2015.

[6] A. Ramesh, O. Chandra Sekhar, M. Siva Kumar (2018). A Novel Three Phase Multilevel Inverter with Single Dc Link For Induction Motor Drive Applications. International Journal of Electrical and Computer Engineering (IJECE), 8(2), pp. 763-770.

[7] Nayak, B., \& Sahu, S. (2019). Parameter estimation of DC motor through whale optimization algorithm. International Journal of Power Electronics and Drive Systems (IJPEDS), 10(1), 83.

[8] Solihin, M. I., Wahyudi, \& Legowo, A. (2010). Fuzzy-tuned PID anti-swing control of automatic gantry crane. Journal of Vibration and Control, 16(1), pp.127-145.

[9] Sakawa, Y., \& Nakazumi, A. (1985). Modeling and control of a rotary crane. Journal of Dynamic Systems, Measurement, and Control, 107(3), pp.200-206.

[10] Colby, R. S. (2000). U.S. Patent No. 6,163,472. Washington, DC: U.S. Patent and Trademark Office.

[11] Petru, L., \& Mazen, G. (2015). PWM control of a DC motor used to drive a conveyor belt. Procedia Engineering, 100, pp. 299-304.

[12] Shen, Y., \& Xia, X. (2014). Adaptive parameter estimation for an energy model of belt conveyor with DC motor. Asian Journal of Control, 16(4), pp.1122-1132.

[13] BETZ, Robert Eric; MIRZAEVA, Galina; SUMMERS, Terrence J. A Dynamic dynamometer for testing of mining DC motors. In: 2010 IEEE Industry Applications Society Annual Meeting. IEEE, 2010. pp.1-8.

[14] Thomas, Neenu, and Dr P. Poongodi, "Position control of DC Motor using genetic algorithm based PID controller", Proceedings of the World Congress on Engineering, 2009, vol. 2, pp. 1-3.

[15] Xue, Dingyu, Chunna Zhao, and YangQuan Chen, "Fractional order PID control of a DC-Motor with elastic shaft: a case study", American Control Conference, IEEE, 2006, pp.1-6.

[16] Yao, Jianyong, Zongxia Jiao, and Dawei Ma,"Adaptive robust control of DC Motors with extended state observer", IEEE Transactions on Industrial Electronics Vol 61.7, 2014, pp. 3630-3637.

[17] Bosco, Maycon Chimini, et al,"Estimation of parameters and tuning of a speed PI of permanent magnet DC Motor using differential evolution", Electric Machines and Drives Conference (IEMDC), IEEE International,2017,pp.1-6.

[18] Trong-Thang Nguyen (2019). The neural network-based control system of direct current motor driver. International Journal of Electrical and Computer Engineering (IJECE), 9(2), pp. 1445-1452.

[19] Xue, D., Zhao, C., \& Chen, Y. (2006, June). "Fractional order PID control of a DC-motor with elastic shaft: a case study”. In IEEE 2006 American control conference. pp.1-6. 
[20] Obaid, B. A., Saleh, A. L., \& Kadhim, A. K. (2019). Resolving of optimal fractional PID controller for DC motor drive based on anti-windup by invasive weed optimization technique. Indonesian Journal of Electrical Engineering and Computer Science (IJEECS), 15(1), pp. 95-103.

[21] Trong, T. N. (2017). The Control Structure for DC Motor based on the Flatness Control. International Journal of Power Electronics and Drive Systems (IJPEDS), 8(4), 1814-1821.

[22] 13Trong-Thang Nguyen (2019). The linear quadratic regular algorithm-based control system of the direct current motor. International Journal of Power Electronics and Drive Systems (IJPEDS), 10(2), pp. 768-776.

[23] Kim, T., Shim, H., \& Cho, D. D. (2016, December). "Distributed Luenberger observer design". In 2016 IEEE 55th Conference on Decision and Control (CDC) (pp. 6928-6933). IEEE.

[24] Andersson, A., \& Thiringer, T. (2018). Motion sensorless ipmsm control using linear moving horizon estimation with luenberger observer state feedback. IEEE transactions on transportation electrification, 4(2), 464-473.

[25] Hicham Serhoud, Djilani Benattous (2018). Sensorless Control of Brushless Doubly-Fed Generator Using Luenberger Observer Based Wind Energy Conversion Systems. International Journal of Applied Power Engineering (IJAPE), 7(2), pp. 188-776. 